\title{
Antimicrobial potentiality of green synthesized iron oxide nanoparticles by Penicillium roqueforti
}

\author{
A. T. Ali ${ }^{1}$; N. Elewa²; N. A. Elbostany ${ }^{1}$; Y. M. Shetaia ${ }^{3}$; M. Swilm ${ }^{4}$ \\ ${ }^{1}$ Special food and Nutrition Department, Food Technology Research Institute, Agriculture Research Centre, Giza, Egypt. \\ ${ }^{2}$ Dairy Science and Technology Department, Faculty of Agriculture, Fayoum University, Fayoum, Egypt. \\ ${ }^{3}$ Microbiology Department, Faculty of Science, Ain Shams University, Cairo, Egypt. \\ ${ }^{4}$ Botany Department, Faculty of Science, Banha University, Al Qalyubiyah, Egypt.
}

\begin{tabular}{l} 
ART I CLE IN FO \\
\hline Received 13 October 2021 \\
Accepted 19 October 2021 \\
\hline Keywords \\
Iron oxide nanoparticles, \\
TEM, \\
XRD, \\
Penicillium roqueforti, \\
Foodborne pathogens. \\
Correspondence \\
A. T. Ali \\
E-mail \\
alyaatalaatg86@gmail.com
\end{tabular}

\begin{abstract}
The invasion of foodborne pathogens remains a serious problem for researchers and regulators in the food industry. The introduction of a new type of potent antibacterial agent is of great importance for controlling bacteria and fungi. This study aimed to investigate a novel antimicrobial agent, such as iron oxide nanoparticles (IONPs), which are biosynthesized by a simple, fast, eco-friendly, and efficient method using Penicillium roqueforti. The obtained iron oxide nanoparticles were covered by $\mathrm{SiO}_{2}$ layer using stöber method. The biosynthesized nanoparticles were characterized by UV-Vis spectroscopy, energy dispersive X-ray (EDX), transmission electron microscopy (TEM), and X-ray diffraction (XRD). Antibacterial activity of the nanoparticles with different concentrations of 50,100,150, and 200 $\mu \mathrm{g} / \mathrm{ml}$ was examined against Gram-positive bacteria (Staphylococcus aureus ATCC 25923 and Bacillus subtilis ATCC 6633) and Gram-negative bacteria (Salmonella typhimurium ATCC 14028 and Escherichia coli ATCC 8739) by agar well diffusion and kinetic bacterial growth methods. While, the antifungal activity of nanoparticles was tested against Aspergillus niger, Aspergillus fumigatus, and Aspergillus flavus using the dry weight mycelial method. According to UV-Vis spectroscopic study, the wavelength band observed in the region 204-266 nm, indicating the formation of iron oxide nanoparticles. In addition, spheres of 5-16 nm-sized iron oxide nanoparticles were confirmed via TEM. Also, the results showed that the modified silica nanoparticles had more significant antimicrobial activity than the iron oxide nanoparticles.
\end{abstract}

\section{Introduction}

Food contamination is a common public health problem. Contamination can be chemical, physical, or microbial induced, and bacteria and fungi are the most common food contaminants ${ }^{[1]}$. The symptoms of food contamination depend on the type of pathogen; however, the most common symptoms are abdominal pain and cramps, diarrhea, nausea, and vomiting. In many cases, food poisoning is mild, but in young patients, the elderly, pregnant women, and immunosuppressed patients (such as diabetes, cancer, HIV/AIDS, and transplant patients), severe food poisoning may require hospitalization ${ }^{[2]}$. 
Nanoparticle development has regained interest in the antimicrobial effects of metals, which declined following the widespread application of modern synthetic antibiotics [3]. Theoretically, nanoparticles can easily penetrate the cell membrane of microorganisms, and their direct action involves depolarizing the membrane, resulting in compromised cell integrity ${ }^{[4]}$. Once in the cell, reactive oxygen species are produced, followed by lipid peroxidation and DNA damage ${ }^{[5-7]}$, as well as the release of metal ions that affect cell homeostasis and protein coordination ${ }^{[8]}$. Several methods have been developed to synthesize metal nanoparticles, including physical, chemical ${ }^{[9]}$, and biological ${ }^{[10]}$ methods. Chemical and physical methods involve toxic chemicals and highly biologically hazardous and very costly compounds [11]. Biological processes have been recommended as ecofriendly, economical, reliable, and straightforward, fast substitutes ${ }^{[12]}$ including different biological sources, such as plant extracts ${ }^{[13]}$, fungi ${ }^{[14]}$, yeast and algae ${ }^{[15]}$, and bacteria ${ }^{[16]}$. Fungi are suitable for the green synthesis of nanoparticles compared to other microorganisms because of their simple handling, fast growth rate, and high yield ${ }^{[17]}$. El-Baz et al. ${ }^{[18]}$ concluded that a simple process for the biosynthesis of new monodisperse-stabilized silver nanoparticles was achieved using the fungal Monascus purpureus culture filtrate as a safe and commercially available microorganism. The genus Penicillium was selected for the biosynthesis of iron oxide nanoparticles as it is one of the largest groups of fungi containing more than 200 specified types. Also, the species of Penicillium are ubiquitous fungi because of their undemanding nutritional requirements and their ability to grow over a wide range of conditions and environments ${ }^{[19]}$.

Metal nanoparticles, especially iron oxide nanoparticles (IONPs), have received special attention due to their various technical applications, such as biosensors, antibacterial activity, food preservation, magnetic resonance imaging, and targeted drug delivery [20]. Furthermore, iron oxide nanoparticles belong to the nontoxic and biocompatible materials category due to the presence of $\mathrm{Fe}(\mathrm{II} / \mathrm{III})$ ions ${ }^{[21]}$. $\mathrm{SiO}_{2}$ is a typical IONP-coating material because it can improve the dispensability of IONPs in solution and make it more stable and protected in acidic media [22]. Therefore, this study aims to biosynthesize iron oxide nanoparticles using Penicillium roqueforti, characterize and modify its surface with $\mathrm{SiO}_{2}$, and evaluate their antimicrobial efficacy.

\section{Material and methods}

\subsection{Materials}

In this study, some foodborne Gram-positive bacteria (Staphylococcus aureus ATCC 25923 and Bacillus subtilis ATCC 6633) and Gram-negative bacteria (Salmonella typhimurium ATCC 14028 and Escherichia coli ATCC 8739) were provided by Food Technology Research Institute, Agriculture Research Center. Tested fungal strains (Aspergillus niger, Aspergillus flavus, and Aspergillus fumigatus) were provided by the Microbiology Department, Faculty of Science, Ain Shams University, Cairo, Egypt. Penicillium roqueforti was isolated from random semi-dry Roquefort cheese (Danish-blue cheese) purchased from a hypermarket in Cairo.

Ferrous chloride tetrahydrate (99\%) $\mathrm{FeCl}_{2} .4 \mathrm{H}_{2} \mathrm{O}$ and ferric chloride hexahydrate $(99 \%)\left(\mathrm{FeCl}_{3} 6 \mathrm{H}_{2} \mathrm{O}\right)$, tetraethyl-orthosilicate (TEOS), ethanol ( $90 \%)$, and $\mathrm{NH}_{4} \mathrm{OH}$.

Nutrient broth and agar, MacConkey agar, potato dextrose agar (PDA) medium, and Czapex dox broth medium were purchased from the Egyptian International Center for Import, Cairo, Egypt.

\subsection{Isolation of Penicillium roqueforti}

Isolation was performed by serial dilution and spread plate method. One Gram of blue- cheese sample was serially diluted in sterile distilled water to get concentrations from $10^{-1}$ to $10^{-4}$. A volume of $0.1 \mathrm{ml}$ of each dilution was transferred aseptically to PDA (Himedia, India) plates containing miphenicol (250 mg) (Misr, Co.) to inhibit bacterial growth. The plates were incubated at $28^{\circ} \mathrm{C}$ for three days. The fungal isolate was further subcultured on the PDA plates to obtain a pure fungal culture. The fungal isolate was identified by ITS sequencing.

\subsection{Genomic DNA extraction}

DNA extraction was conducted according to the instructions provided by Quick-DNA Miniprep Kit (Sigma Scientific Services Co., Egypt).

\section{PCR and DNA sequencing of ITS1-5.8S-ITS2 region rDNA}

\section{of fungal species}

PCR fragments for sequence analysis were generated using primers ITS4 and ITS5 covering the internal transcribed spacer 1 (ITS1), 5.8S, and ITS2 region of the ribosomal DNA were described by White et al. ${ }^{[23]}$. For each $20-\mu$ reaction containing $2.5 \mu$ of each primer (10 pm); ITS5 (5 '-GGAAGTAAAAGTCGTAACAAGG-3') and ITS4 (5`-TCCTCCGCTTA TTGATATGC- 3`) (My Taq Red Mix-UK), 
$2.5 \mu \mathrm{l}$ of genomic DNA $(5 \mu \mathrm{g} / \mathrm{ml})$, and one PCR-Gold Master-Mix bead (My Taq ${ }^{\mathrm{TM}}$ Red Mix-UK; buffers, dNTP, enzyme, stabilizers, Tris- $\mathrm{HCl}, \mathrm{KCl}$, and $\mathrm{MgCl} 2$ ). Amplification was performed using a PCR Thermal Cycler (My Taq ${ }^{\mathrm{TM}}$ Red Mix - UK) with an initial denaturation at $96^{\circ} \mathrm{C}$ for $5 \mathrm{~min}, 35$ cycles of denaturation at $94^{\circ} \mathrm{C}$ for $30 \mathrm{sec}$, annealing at $52^{\circ} \mathrm{C}$ for $30 \mathrm{sec}$, extension at the $72^{\circ} \mathrm{C}$ for $80 \mathrm{sec}$, and a final extension at the $72^{\circ} \mathrm{C}$ for $10 \mathrm{~min}$. The PCR reaction products were sequenced directly using a Big-Dye terminator reagent kit containing Taq polymerase using the protocol recommended by the manufacturer, an ABI $3730 \mathrm{xl}$ automated DNA sequencer (GATC, UK) using forward and reverse primers.

\subsection{Biosynthesis of iron oxide nanoparticles}

The method described by Mazumdar \& Haloi ${ }^{[24]}$ was followed to study iron oxide nanoparticle formation using Penicillium roequeforti. The fungal isolates were inoculated into potato dextrose broth in a $250 \mathrm{ml}$ Erlenmeyer flask and then was incubated in a shaking incubator at $28^{\circ} \mathrm{C}, 200 \mathrm{rpm}$ for $72 \mathrm{~h}$. The obtained fungal biomass was filtrated using Whatman filter paper No.1. The harvested fungal mycelia were resuspended in $100 \mathrm{ml}$ sterilized distilled water in a $250 \mathrm{ml}$ Erlenmeyer flask. They were kept in a shaking incubator at the $28^{\circ} \mathrm{C}$ for $6 \mathrm{~h}$ and filtrated using Whatman filter paper No.1 then washed three times using sterile distilled water (to remove any traces of medium attached to fungal mycelia). A stock solution of ferric chloride hexahydrate $\left(10^{-3} \mathrm{M}\right)$ (PubChem, USA) and ferrous chloride tetrahydrate $\left(10^{-3} \mathrm{M}\right)$ (PubChem, USA) by the ratio 2:1 was prepared. Then, $10 \mathrm{~g}$ of wet biomass was added to $90 \mathrm{ml}$ mixture of salt solution and was incubated again for $24 \mathrm{~h}$ at $28^{\circ} \mathrm{C}$ in a dark-shaking incubator at $150 \mathrm{rpm}$. The visual change in the color of the reaction mixture was considered a positive result for the biosynthesis of IONPs. To separate the nanoparticles from the fungal mycelia, the mycelia were filtrated by filter paper. The filtrate was centrifuged at $4000 \mathrm{rpm}$ for $10 \mathrm{~min}$, washed three times with deionized water, and then dried for three days at $60^{\circ} \mathrm{C}$ in the oven. The obtained iron oxide nanoparticles' powder was used for characterization. Control salt solution (without fungus) also was run along with the experimental flasks.

\subsection{Coating of the nanoparticles with silica}

IONPs $(2 \mathrm{~g})$ was diluted with $40-\mathrm{ml}$ water and $120 \mathrm{ml}$ ethanol ( $90 \%$ ) (ChemLab, Belgium), and then 3.0-ml ammonia aqueous (25 wt\%) (Sphinx, Egypt) were added.
The resultant solution was well-mixed by ultrasonic vibration for $15 \mathrm{~min}$. Finally, $0.9 \mathrm{~g}$ of TEOS (Sphinx, Egypt) diluted in $20 \mathrm{ml}$ ethanol was slowly added to this solution under continuous mechanical stirring. After stirring for $12 \mathrm{~h}$, the obtained nanocomposite product was collected by magnetic separation and washed twice with ethanol [25].

\subsection{Characterization of iron oxide nanoparticles and modified iron oxide}

The biosynthesized iron oxide nanoparticles and the modified Si-IONPs were subjected to various characterization studies to understand the specific properties, such as optical, structural, morphological, and particle sizes. UV-Vis spectroscopy (a Shimadzu, UV-2450 UV-spectrophotometer), energy dispersive Xray (EDX), transmission electron microscope (TEM, 200kv TEM, JEM-2100 Electron Microscope), and X-ray diffractometer (XRD) (Shimadzu XRD-6000) were used.

2.7 Assessment of the antimicrobial activity of IONPS and Si-IONPS

Different concentrations of IONPs and Si-IONPs (50, 100,150 , and $200 \mu \mathrm{g} / \mathrm{ml}$ ) were prepared and tested against some bacteria, such as Gram-positive (Staphylococcus aureus ATCC 25923 and Bacillus subtilis ATCC 6633), and Gram-negative (Salmonella typhimurium ATCC 14028 and Escherichia coli ATCC 8739) using a modified Kirby-Bauer well diffusion method [26]. Briefly, the pure culture of each microorganism was subcultured in nutrient broth (Oxoid,UK), incubated at $37 \pm 2^{\circ} \mathrm{C}$ for $24 \mathrm{~h}$ on a rotary shaker at $160 \mathrm{rpm}$. For bacterial growth, the $100 \mu \mathrm{l}$ fresh cultures having $10^{6} \mathrm{CFU} / \mathrm{ml}$ of each test organism were inoculated on nutrient agar plates. Plates were left standing for $10 \mathrm{~min}$ to let the culture get absorbed. Then four $(8 \mathrm{~mm})$ wells were punched into the nutrient agar plates. Using a micropipette, $100 \mu l$ of nanoparticles suspension was poured into the wells on all plates. After overnight incubation at $37 \pm 2^{\circ} \mathrm{C}$, the diameter of inhibition zones was measured $(\mathrm{mm})$.

The growth kinetic study (concentration and timedependent antibacterial activity) was conducted according to the method of Margabandhu et al. ${ }^{[27]}$ with some modifications. For bacterial growth, an inoculum of $250-\mu \mathrm{L}$ fresh culture containing $1 \times 10^{8} \mathrm{CFU} / \mathrm{ml}$ of each test bacteria was subcultured in $100 \mathrm{ml}$ of nutrient broth incubated at $37 \pm 2^{\circ} \mathrm{C}$ on a shaker at $120 \mathrm{rpm}$ for $2 \mathrm{~h}$. Then, the different concentrations of IONP and Si-IONP were added and incubated with the control flasks of each pure 
bacterial culture for $48 \mathrm{~h}$ at $37 \pm 2^{\circ} \mathrm{C}$ under $120 \mathrm{rpm}$ shaking. The optical density of the collected cell suspension was measured at $595 \mathrm{~nm}$ at a regular time interval of $6 \mathrm{~h}$ using a Shimadzu, UV-Vis spectrometer (modification).

Nanoparticles were tested for their ability to reduce the mycelium dry weight. So, the antifungal activity of nanoparticles was tested against Aspergillus niger, Aspergillus fumigatus, and Aspergillus flavus using dry weight mycelia ${ }^{[28]}$. Sterilized Czapex dox broth (Oxoid; $100 \mathrm{ml}$ ) was inoculated with $1 \mathrm{ml}$ of spore suspension of tested fungal strains. The concentrations 50, 100, 150 , and $200 \mu \mathrm{g} / \mathrm{ml}$ of IONPs and Si-IONPs were added. Also, the control flasks containing $100 \mathrm{ml}$ Czapex dox broth were inoculated by fungus only (without nanoparticles) and run along with the experiment. Then, all experimental flasks were incubated at $28 \circ \mathrm{C}$ for $7 \mathrm{~d}$. To measure the fungal growth in a liquid medium after incubation, the cultures were heat treated by being autoclaved at $121^{\circ} \mathrm{C}$ for $30 \mathrm{~min}$ to kill the spores and vegetative mycelium as is suggested for safety reasons. The biomass was harvested by filtration of the cultures using filter papers, washed with distilled water, and dried at $80^{\circ} \mathrm{C}$ for $16 \mathrm{~h}$ (till constant weight). Then the weight of dried mycelium was determined.

The percentage decrease of fungal biomass $(\%)=$

$$
(C-T) /(C) \times 100
$$

Where: $C$ is the dry weight of the control fungal mycelia and $\mathrm{T}$ is the dry weight of the fungal mycelia incubated with different concentrations of nanoparticles. All experiments were replicated three times for statistical analysis.

\subsection{Statistical analysis}

Post Hoc test: Duncan's test $(P \leq 0.05)$ was used to establish the significance of differences ${ }^{[29]}$.

\section{Results}

\subsection{Isolation and molecular identification of the fungal isolate}

The fungal colonies initially appeared as white and eventually turned blue-green, gray-green, and olivegray over time. The hyphae are septate, and conidiophores are long and smooth; phial conidia are produced on phialides with distinctive brush-shaped configurations. The presumptive morphologic identification of the fungal isolate revealed Penicillium roqueforti. The sequences of the ITS1-5.8S-ITS2 rDNA region of the isolate was from $43-519 \mathrm{bp}$. The NCBI GenBank was accessed to identify the isolated species through BLAST homology searches using the obtained ITS data. The ITS data of isolated $P$. roqueforti was a $100 \%$ identical P. roqueforti MK805460.1.

\subsection{Biosynthesis of iron oxide nanoparticles (IONPS)}

The sign of the formation of iron oxide nanoparticles was a change in the color of the iron salt solution from light-yellow to brown after $24 \mathrm{~h}$, as shown in Fig. 1a1, but there was no change in the control flask under the same conditions Fig. 1a2. As shown in Fig. 1b, fine brick-colored deposits were visually observed.
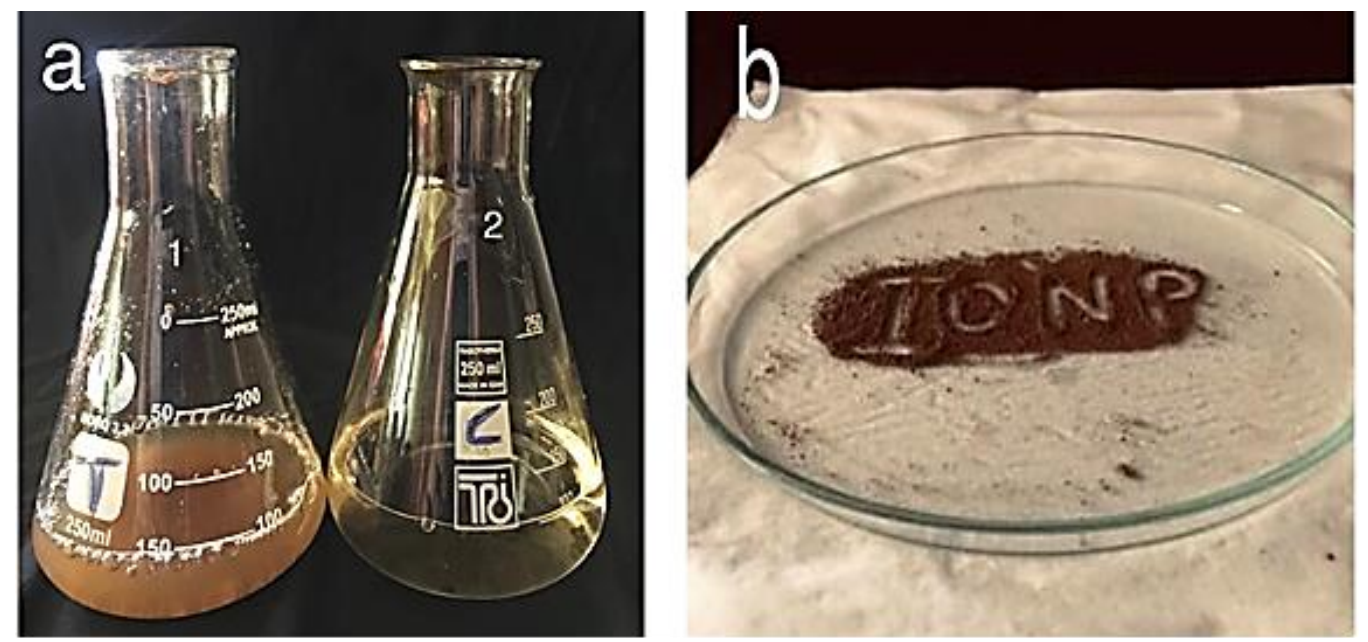

Fig. 1 Showed the signs of the synthesized Iron oxide nanoparticles, (a1) illustrated the change of color of the salt solution of iron while (a2) illustrated the control without the fungus, (b) illustrated the purified powder of iron oxide nanoparticles 


\subsection{Characterization of iron oxide nanoparticles}

As shown in Fig. 2a, in the UV/V spectrum analysis, the absorption band of IONP was observed in the region of 204-266 nm. Alternatively, Fig. 2b showed that the peak of the iron oxide nanoparticles coated with the silica core-shell shifted to $277 \mathrm{~nm}$. The EDX spectrum of the biosynthesized iron oxide nanoparticles is shown in Fig. 3a. The elemental profile of IONPs was $6.4 \mathrm{keV}$, and the existence of the elemental iron signal was confirmed. The results in Fig. $3 \mathrm{~b}$ showed the presence of silica peaks at $1.8 \mathrm{keV}$. A typical TEM image of biosynthesized iron oxide nanoparticles was shown in Fig. 4a. The average diameter of the aggregated IONPs was about 5-16 nm, and the morphology of the IONPs was significantly different for the narrow size distribution and spherical shape. The results in Fig. $4 \mathrm{~b}$ clearly showed that the observed nanoparticles contained a uniformly coated $\mathrm{SiO}_{2}$ layer on the surface of the IONPS and the size of Si-IONPS was 16-23 $\mathrm{nm}$. The XRD pattern confirmed the major composition of magnetite and the sites of the diffraction peaks were $11.82^{\circ}, 30.00^{\circ}, 35.24^{\circ}, 44.60^{\circ}$, $57^{\circ}$, and $62.8^{\circ} \mathrm{Fig}$. 5a. While the iron oxide nanoparticles coated by silica was similar to the pure iron oxide nanoparticles except that a slight increase in the background was noted in the region $20^{\circ}<2 \theta<30^{\circ}$ Fig. $5 \mathrm{~b}$.
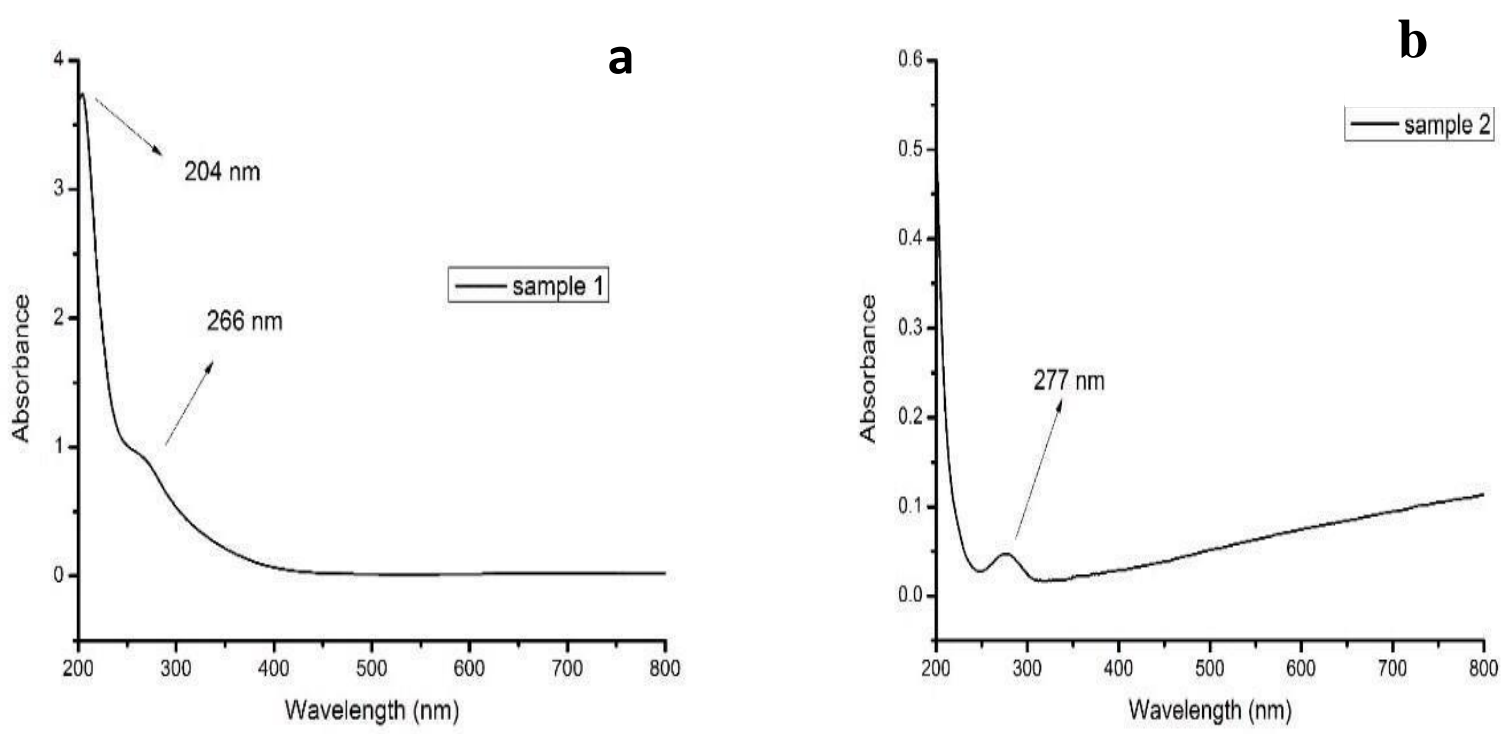

Fig. 2 UV-Vis spectra of biosynthesized iron oxide nanoparticles by Penicillium roqueforti MK805460.1 (a), and iron oxide nanoparticles coated by silica core-shell (b)

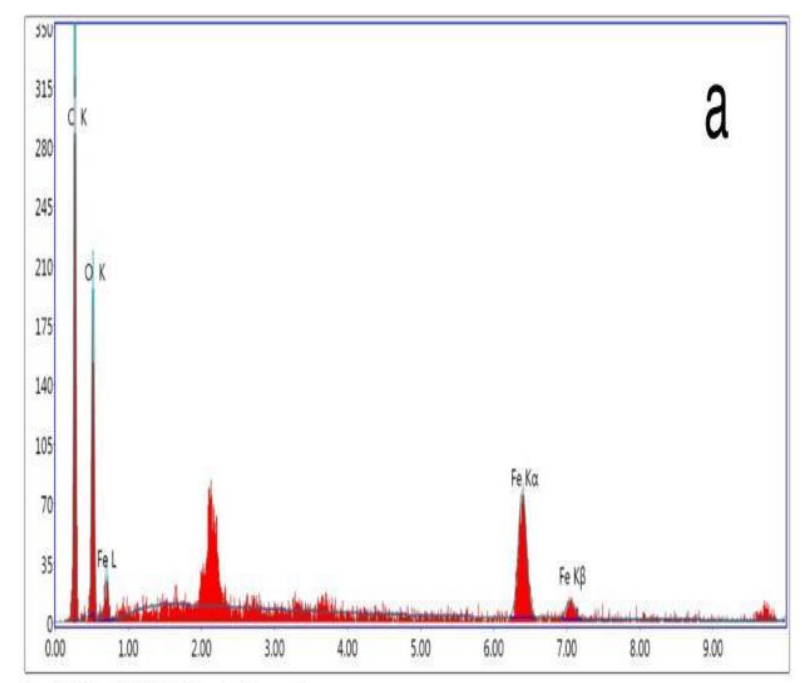

Lsec 30000 Cnts 0000 keV Det Octane Pro Det Reso

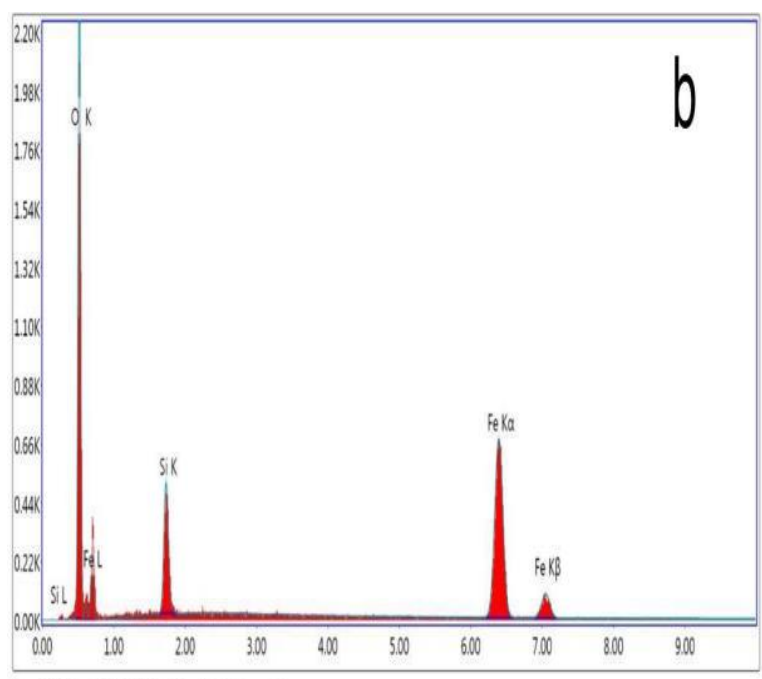

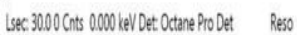

Fig. 3 Energy Dispersive X-ray Spectroscopy (EDX) of Iron oxide nanoparticles (a) and the EDX images of the Si-IONPs (b) 

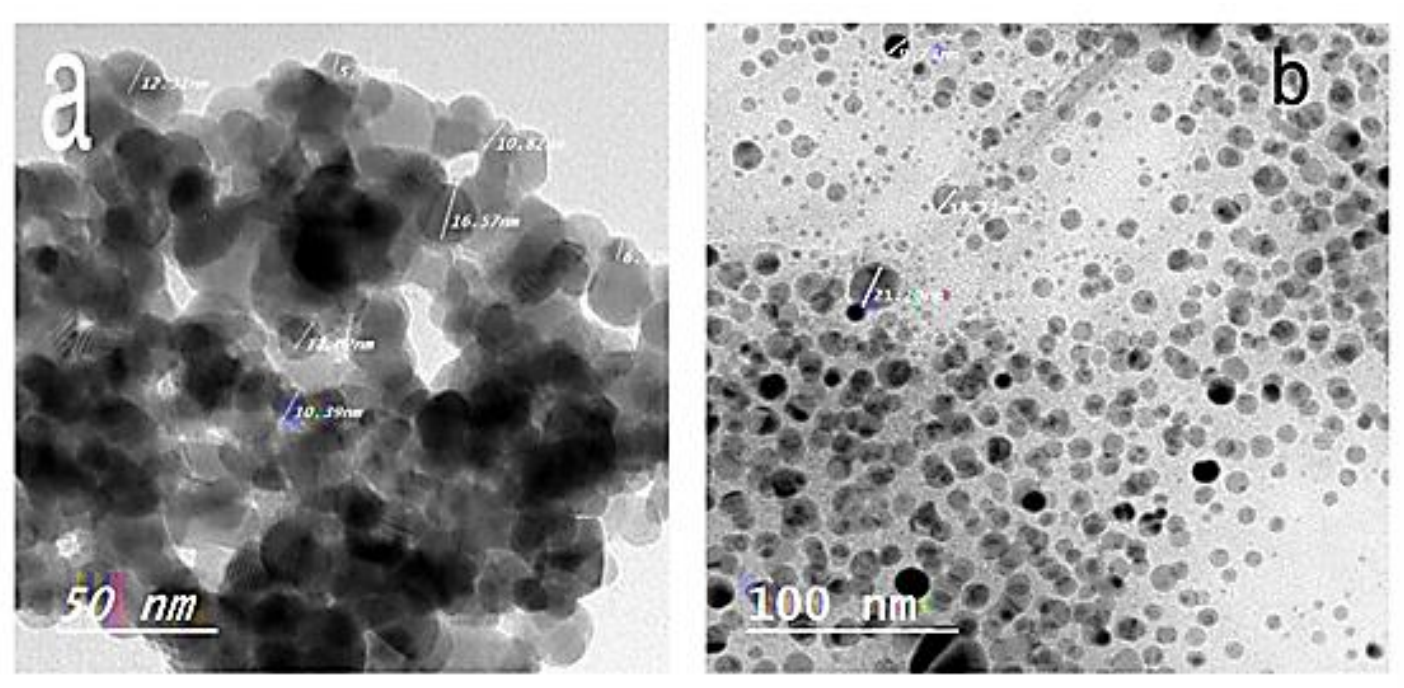

Fig. 4 TEM micrographs of biosynthesized iron oxide nanoparticles (a), and the TEM image of SiIONPs (b)
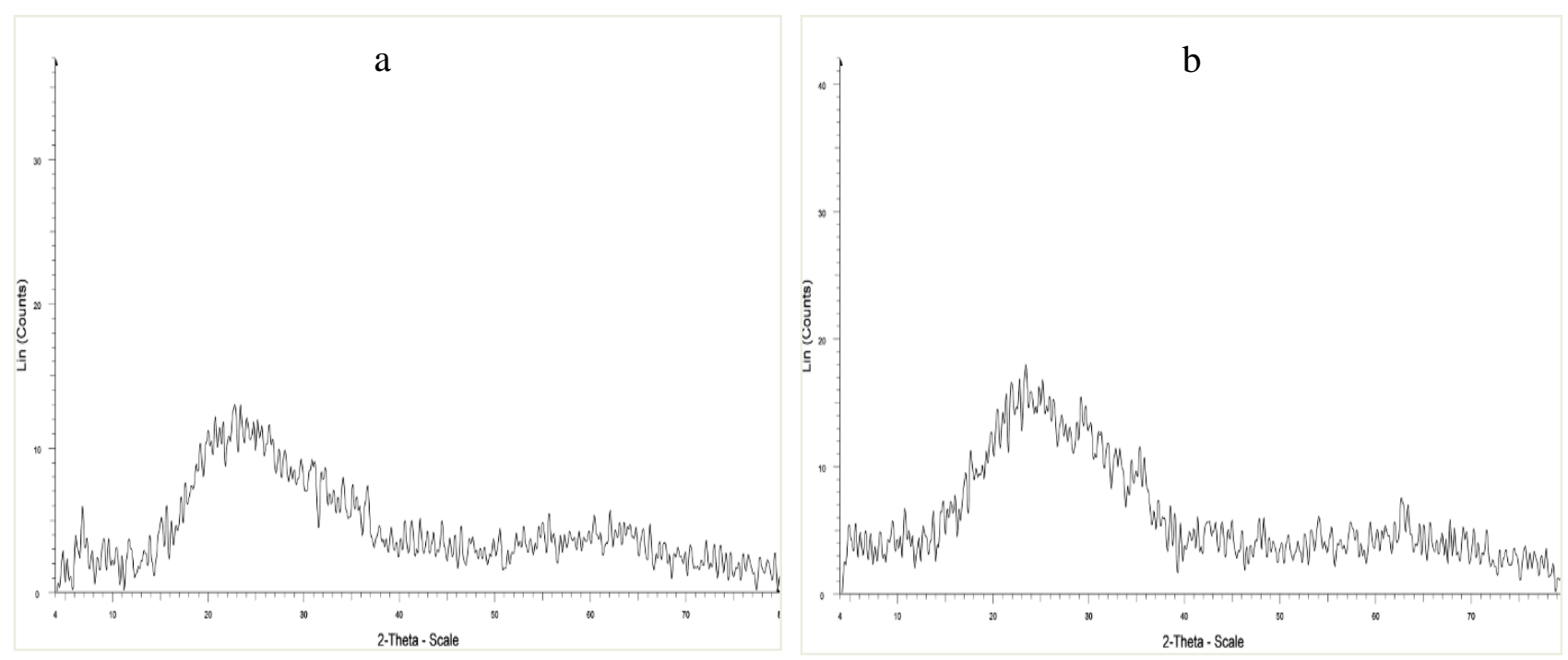

Fig. 5 XRD pattern of the synthesized Iron oxide nanoparticles (a) and The XRD pattern of IONPs coated with silica (b)

\subsection{Assessment of antimicrobial activity}

As shown in Table 1, the results of the antimicrobial activity using the agar well diffusion method of IONPs and Si-IONPs against Gram (+ve) and Gram (-ve) bacteria showed a statistically significant difference between different concentrations. The diameter of the inhibition zone increased with increasing concentrations of IONPS and Si-IONPs. The antibacterial activity of IONPs against Gram (+ve) bacteria was $29.00 \pm 1.00 \mathrm{~mm}$ for Staphylococcus aureus Fig. 6 a, while it was $27.20 \pm 0.17 \mathrm{~mm}$ for Gram (-ve) bacteria Salmonella typhimurium Fig. 7a and $25.33 \pm 58$ $\mathrm{mm}$ for Escherichia coli Fig. 8a at $200 \mu \mathrm{g} / \mathrm{ml}$. The antibacterial activity of Si-IONPs against Gram (+ve) bacteria was $35.33 \pm 0.58$ and $35.00 \pm 1.00 \mathrm{~mm}$ for $B$. subtilis Fig. 9 and S. aureus Fig. 6b, respectively, while it was $28.67 \pm 0.58 \mathrm{~mm}$ and $27.67 \pm 0.58 \mathrm{~mm}$ for $\mathrm{S}$. typhimurium Fig. $7 \mathrm{~b}$ and E. coli Fig. 8b at $200 \mu \mathrm{g} / \mathrm{ml}$, respectively. 


\section{A. T. Ali et al /Egy. J. Pure \& Appl. Sci. 2021; 59(1):29-43}

Table 1 The statistical analysis of antibacterial activity of IONPs and SI-IONPs with different concentrations against Gm (+ve) and Gm (-ve) bacteria

\begin{tabular}{|c|c|c|c|c|c|c|c|c|}
\hline \multirow{3}{*}{ Microorganisms } & \multicolumn{8}{|c|}{ Diameters of inhibition zone (mm) } \\
\hline & \multicolumn{3}{|c|}{ IONPS } & \multicolumn{4}{|c|}{ SI-IONPS } & \multirow[b]{2}{*}{$200 \mu \mathrm{g} / \mathrm{ml}$} \\
\hline & 50 & 100 & 150 & 200 & 50 & 100 & 150 & \\
\hline E. coli & $19.10 \pm 0.85^{\mathrm{fC}}$ & $21.33 \pm 0.58^{\mathrm{eB}}$ & $23.00 \pm 1.00^{\mathrm{dec}}$ & $25.33 \pm 0.58^{\mathrm{bcD}}$ & $21.33 \pm 0.58^{\mathrm{eB}}$ & $23.67 \pm 0.58^{\mathrm{cdB}}$ & $25.67 \pm 0.58^{b c}$ & $27.67 \pm 0.58^{\mathrm{aB}}$ \\
\hline S. typhimurium & $21.77 \pm 0.40^{d B}$ & $22.67 \pm 0.58^{d B}$ & $25.87 \pm 0.23^{\mathrm{bcB}}$ & $27.20 \pm 0.17^{\mathrm{abc}}$ & $22.67 \pm 0.58^{d B}$ & $25.00 \pm 1.00^{\mathrm{cB}}$ & $27.67 \pm 0.58^{a B}$ & $28.67 \pm 0.58^{a B}$ \\
\hline B. subtilis & $22.87 \pm 0.51^{d B}$ & $25.33 \pm 0.58^{\mathrm{cA}}$ & $30.53 \pm 1.08^{\mathrm{bA}}$ & $31.53 \pm 0.68^{\mathrm{bA}}$ & $27.00 \pm 1.00^{\mathrm{CA}}$ & $32.00 \pm 1.00^{\mathrm{bA}}$ & $34.67 \pm 0.58^{\mathrm{aA}}$ & $35.33 \pm 0.58^{\mathrm{aA}}$ \\
\hline St. aureus & $25.00 \pm 1.00^{\mathrm{eA}}$ & $26.00 \pm 1.00^{\text {deA }}$ & $27.67 \pm 0.58^{\mathrm{cdB}}$ & $29.00 \pm 1.00^{\mathrm{cB}}$ & $26.33 \pm 0.58^{\text {deA }}$ & $32.00 \pm 1.00^{\mathrm{bA}}$ & $33.00 \pm 1.00^{\mathrm{abA}}$ & $35.00 \pm 1.00^{\mathrm{aA}}$ \\
\hline
\end{tabular}

Different small letters indicated significant difference at $(P \leq 0.05)$ among means in the same row, while the different capital letters indicated a significant difference at $(P \leq 0.05)$ among means in the same column
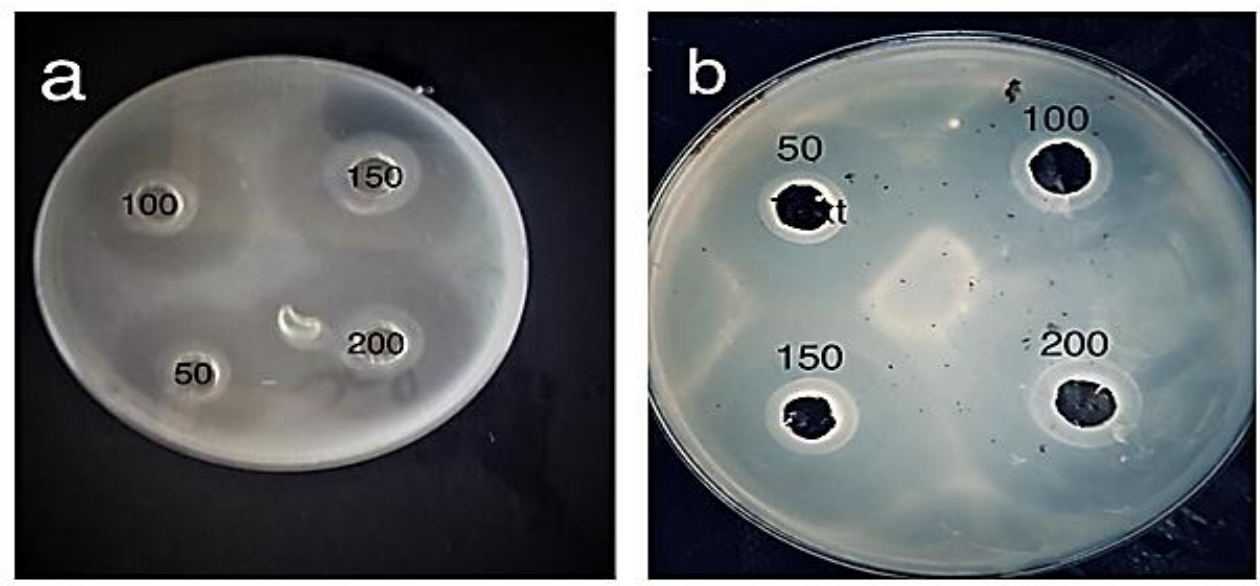

Fig. 6 Antibacterial activity of different concentrations (50, 100, 150, and $200 \mu \mathrm{g} / \mathrm{ml})$ of IONPs (a) and Si-IONPs (b) against St. aureus by agar well diffusion
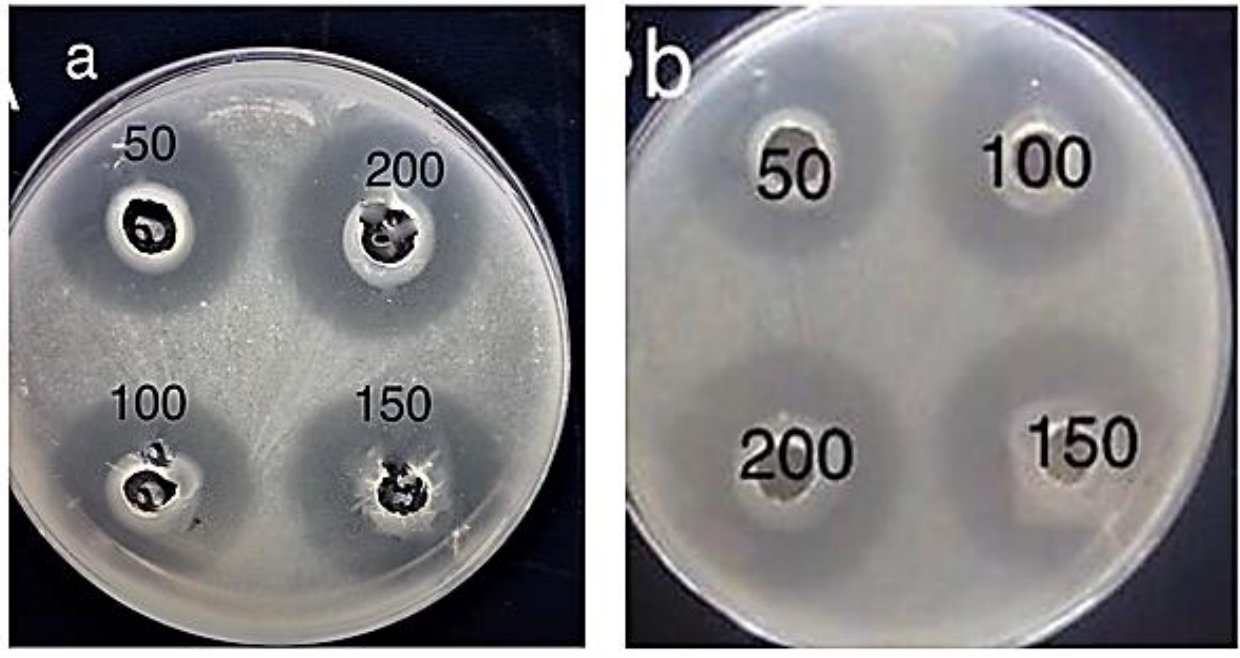

Fig. 7 Antibacterial activity of different concentrations $(50,100,150$, and $200 \mu \mathrm{g} / \mathrm{ml})$ of IONPs (a) and Si-IONPs (b) against $S$. typhimurium by agar well diffusion 

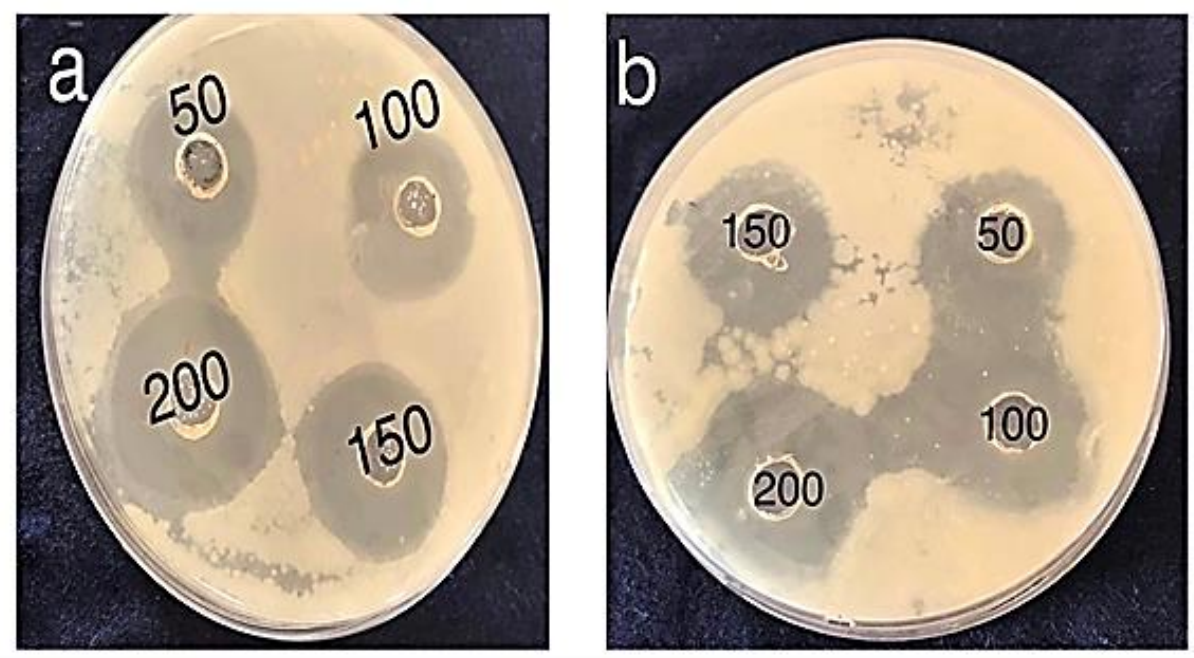

Fig. 8 Antibacterial activity of different concentrations $(50,100,150$, and $200 \mu \mathrm{g} / \mathrm{ml})$ of IONPs (a) and Si-IONPs (b) against E. coli by agar well diffusion

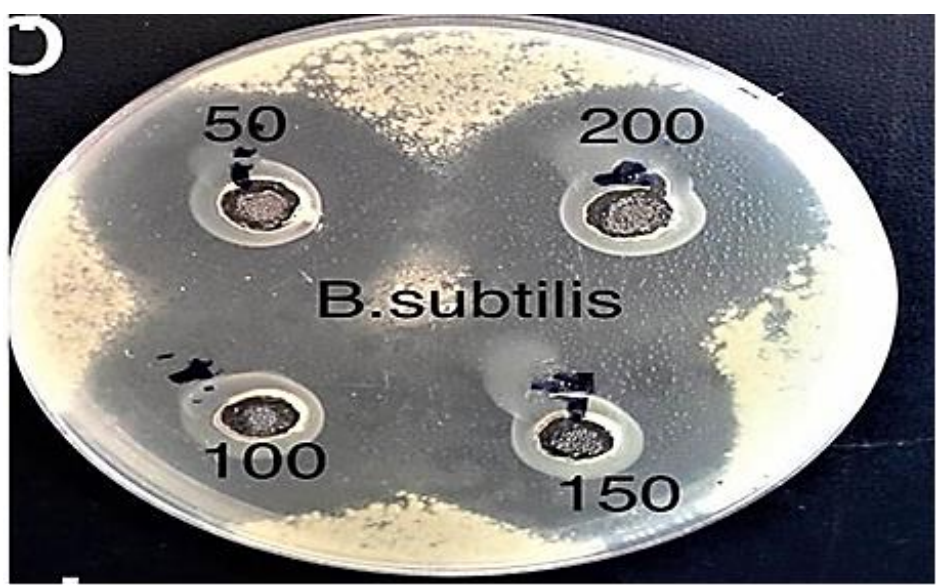

Fig. 9 Antibacterial activity of Si-IONPs at different concentrations (50,100, 150, and $200 \mu \mathrm{g} / \mathrm{ml}$ ) against B.subtilis by agar well diffusion

The antibacterial activity from the growth kinetic analysis showed the microbes to be sensitive at all concentration of the nanoparticles examined. Bacterial inhibition of $B$. subtilis was detected in comparison to control in the presence of IONPs and Si-IONPs at various concentrations, according to the results found in Fig. 10. At $200 \mu \mathrm{g} / \mathrm{ml}$ of IONPs, bacterial cell viability decreased by approximately $40 \%$ Fig. 10a. However, the Si-IONPs had a significant effect on bacterial viability, which reduced by $60 \%$ at $200 \mu \mathrm{g} / \mathrm{ml} \mathrm{Fig.} \mathrm{10b.}$ The growth curve of $S$. aureus was demonstrated in Fig. 11a, and the viability of bacterial cells was reduced by roughly $45 \%$ at $200 \mu \mathrm{g} / \mathrm{ml}$ of IONPs compared with the control sample. While the Si-IONPs had a major impact on S. aureus than IONPs at $200 \mu \mathrm{g} / \mathrm{ml}$, at which the bacterial viability was $65 \%$ less Fig. 11b. The results are shown in Fig. 12a illustrating the growth curve of $E$. coli. The viability of bacterial cells at $200 \mu \mathrm{g} / \mathrm{ml}$ IONPs was reduced by around $40 \%$. For Si-IONPs, bacterial viability at $200 \mu \mathrm{g} / \mathrm{ml}$ concentrations was decreased by $45 \%$ Fig. 12b. At concentration of $200 \mu \mathrm{g} / \mathrm{ml}$ of IONPs and Si-IONPs, the viability of bacterial cells was reduced by roughly $40 \%$ and $55 \%$, respectively, according to the growth curve of $S$. typhimurium Fig. 13a \& b. 

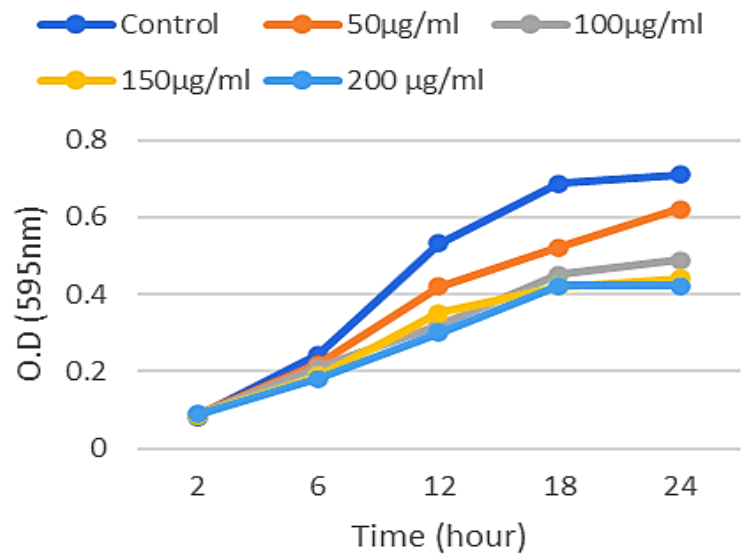

(a)

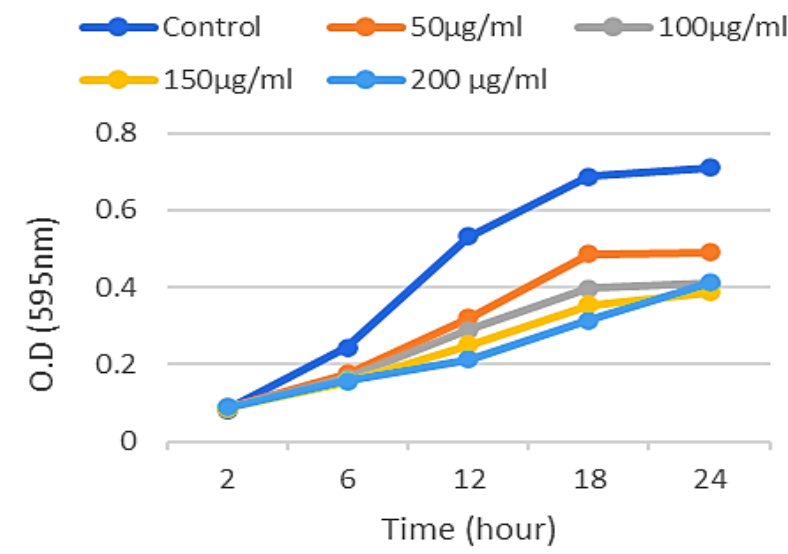

(b)

Fig. 10 Growth kinetics of $B$. subtilis with different concentrations of IONPs (a) and Si-IONPs (b)

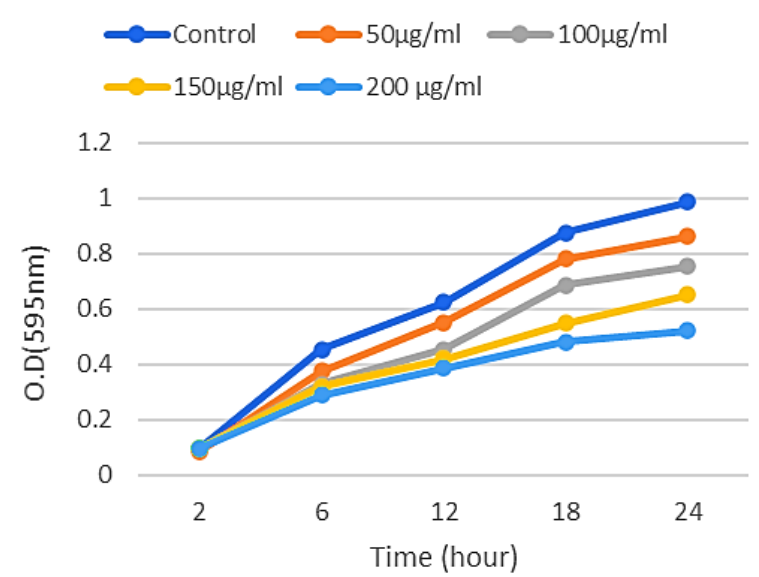

(a)

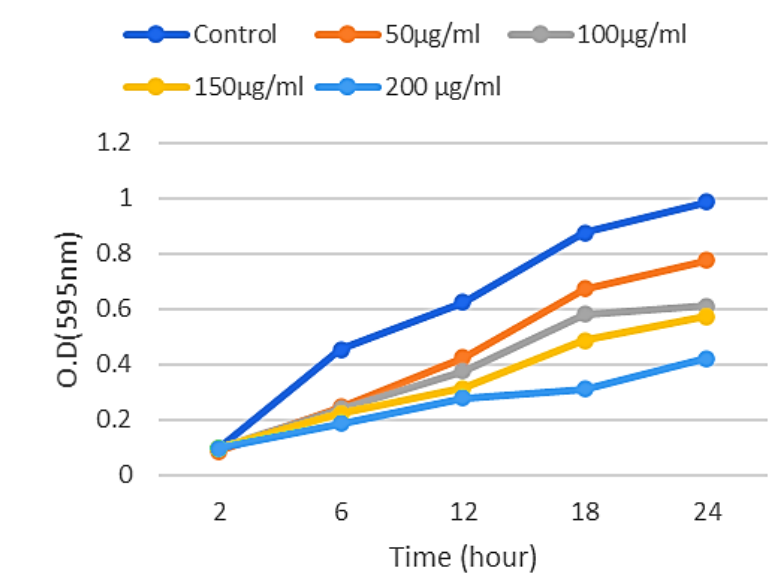

(b)

Fig. 11 Growth kinetics of St. aureus with different concentrations of IONPs (a) and Si-IONPs (b)

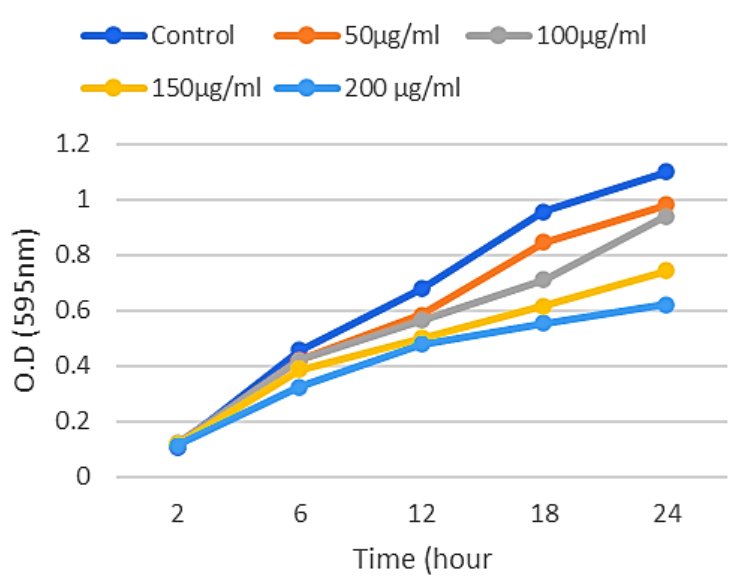

(a)

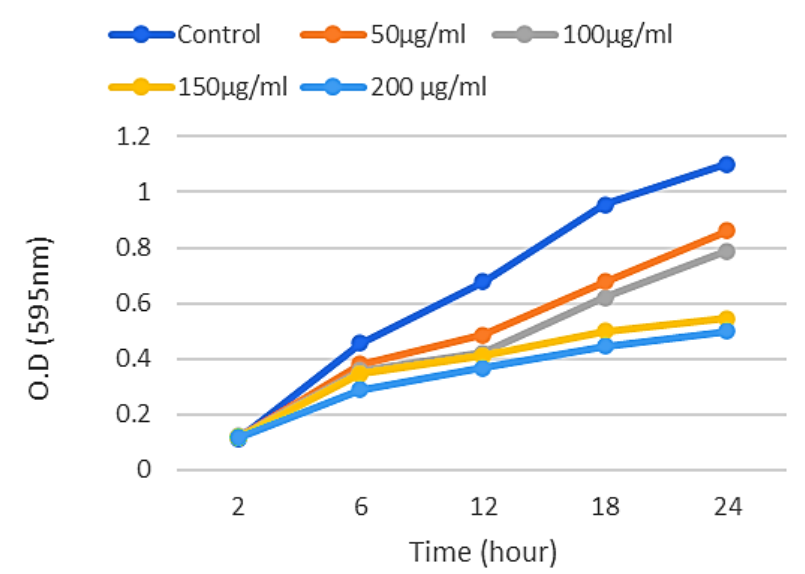

(b)

Fig. 12 Growth kinetics of E. coli with different concentrations of IONPs (a) and Si-IONPs (b) 


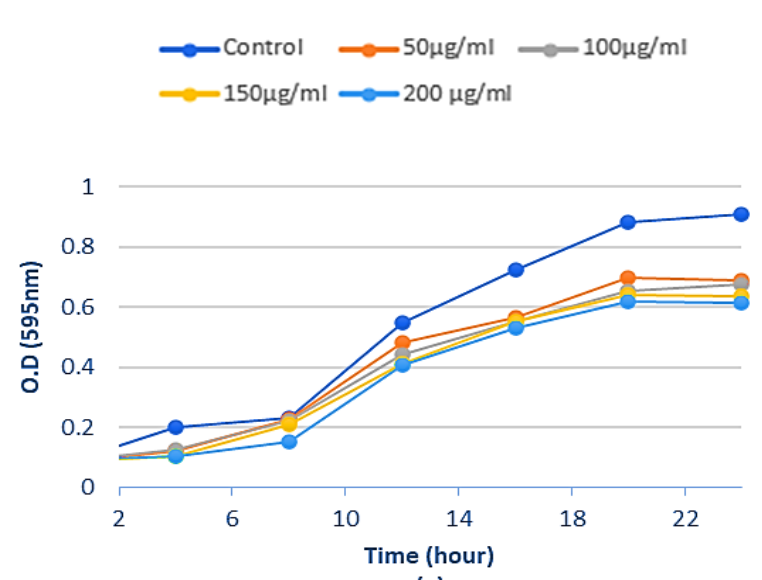

(a)

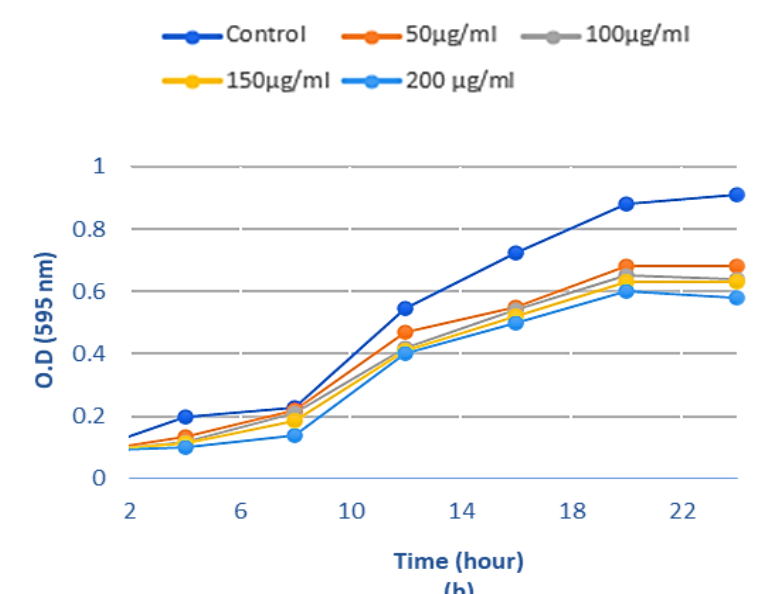

(b)

Fig. 13 Growth kinetics of S. typhimurium with different concentrations of IONPs (a) and Si- IONPs (b)

The results in Fig. 14 showed that the reduction of mycelium dry weight (\%) of Aspergillus niger in both samples IONPs and Si-IONPs at varying concentrations $(50,100,150$, and $200 \mu \mathrm{g} / \mathrm{ml}$ ) was considerably greater than the control. Furthermore, the rate of growth inhibition was substantially dependent on nanoparticles concentration, the higher the concentration, the greater the suppression of mycelia growth. Treatment of $A$. niger with 100 and $200 \mu \mathrm{g} / \mathrm{ml}$ of IONPs was reduced mycelial growth by $22 \%$ and $45 \%$, respectively, but treatment with the same concentrations of Si-IONPs was reduced mycelial growth by $41 \%$ and $58 \%$ in compared to the control.
The results in Fig. 15, all treated samples of both IONPs and modified IONPs in different concentrations showed a substantial $(p<0.05)$ reduction in the mycelium dry weight of $A$. fumigatus in compared with the control except for the IONPs sample at a concentration of $50 \mu \mathrm{g} / \mathrm{ml}$. Compared to the other treated samples, the Si-IONPs sample with a 200 $\mu \mathrm{g} / \mathrm{ml}$ concentration had the lowest mycelium dry weight of fungus. The mycelial growth of the fungus $A$. flavus was reduced by $25 \%$ and $50 \%$, respectively when treated with 100 and $200 \mu \mathrm{g} / \mathrm{ml}$ of IONPs compared with the control Fig. 16. Alternatively, at the same Si-IONPs concentration, the reduction was $39 \%$ and $60 \%$, respectively compared with the control.

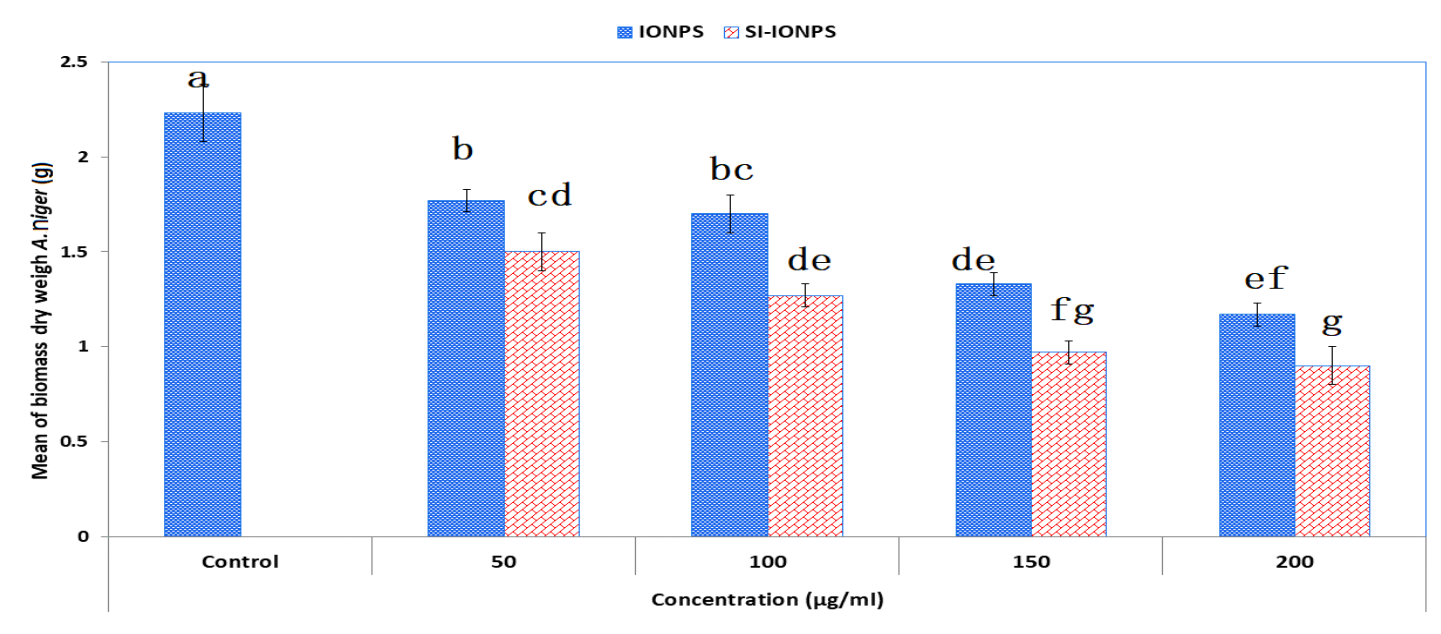

Fig. 14 Effect of antifungal activity of IONPs and Si-IONPS on the reduction of mycelium dry weight of $A$. niger (Letters above columns illustrate the outcome of statistics tests; different letters indicate significant differences at $p<0.05$ among the means of biomass dry weight $(\mathrm{g})$ with different concentrations of IONPS and SI-IONPS) 


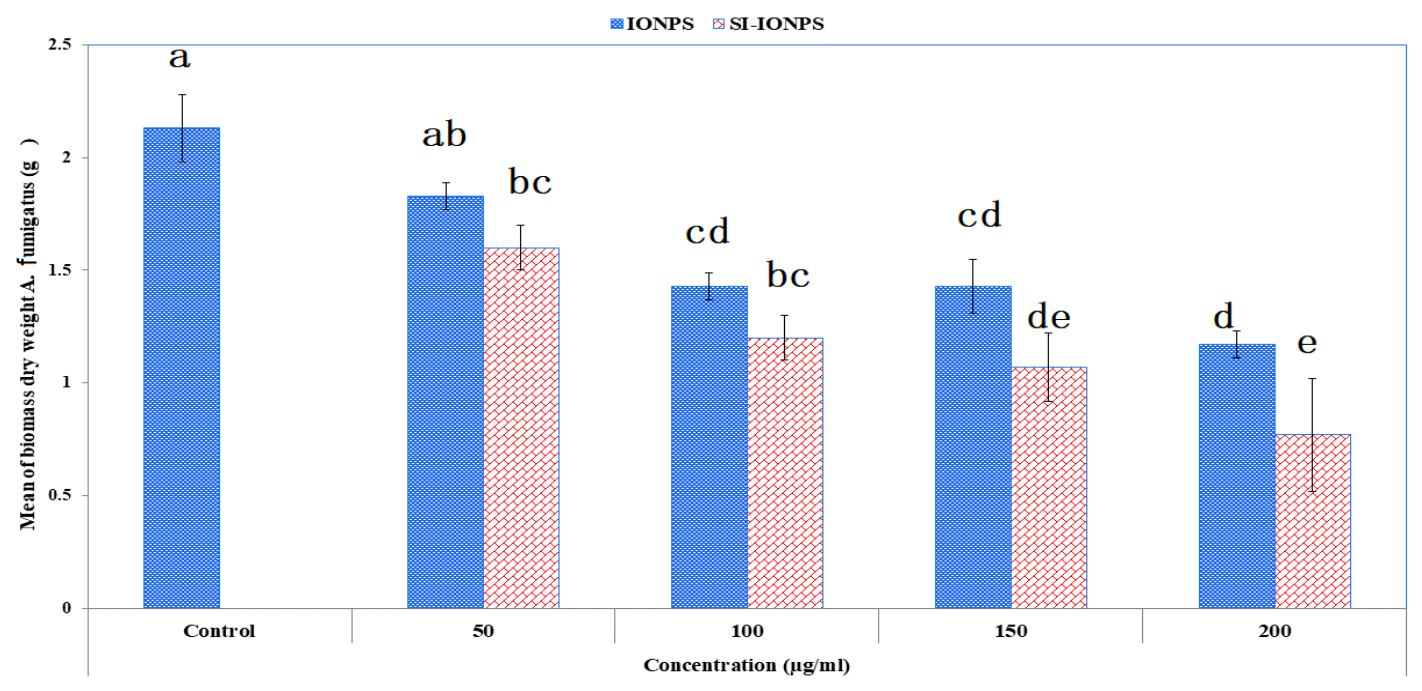

Fig. 15 Effect of antifungal activity of IONPS and SI-IONPS on the reduction of mycelium dry weight of $A$. fumigatus

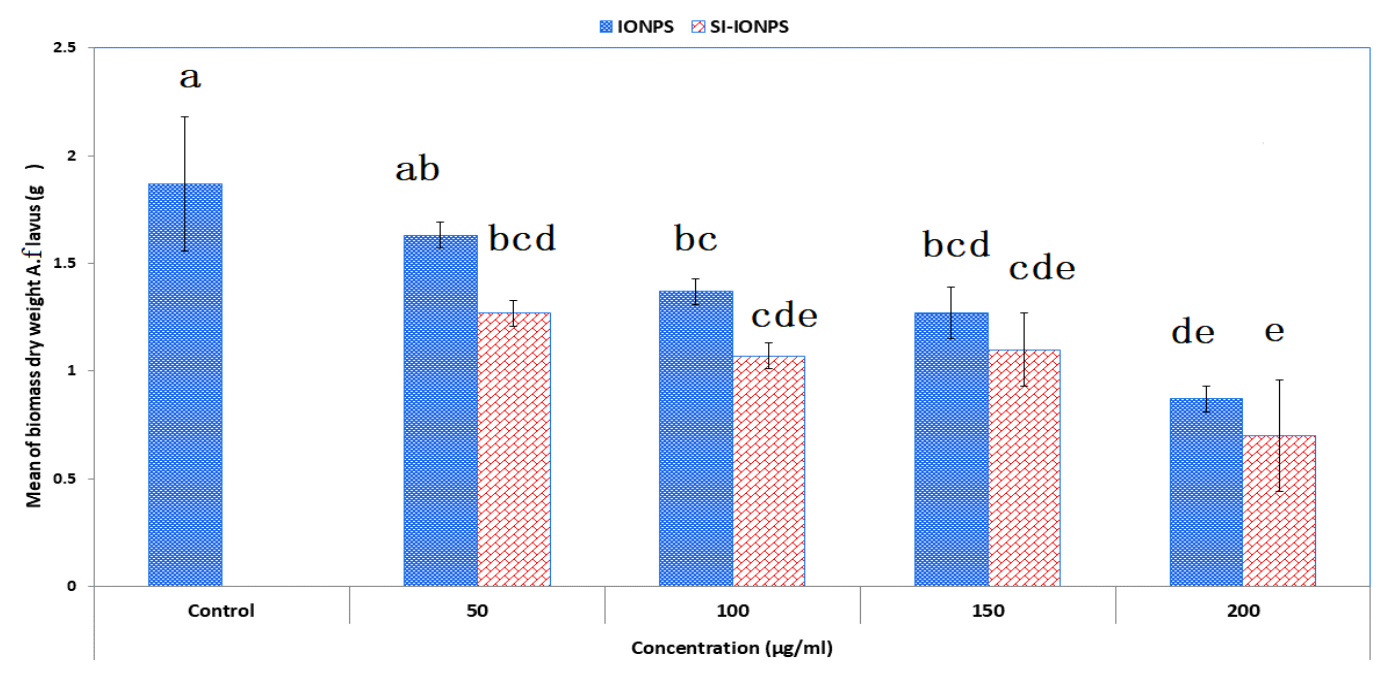

Fig. 16 Effect of antifungal activity of IONPs and Si-IONPs on the reduction of mycelium dry weight of $A$. flavus

\section{Discussion}

The fungus $P$. roqueforti possesses many favorable and ambivalent characteristics, such as favorable growth at moderately acidic $\mathrm{pH}$, low $\mathrm{O}_{2}$ and high $\mathrm{CO}_{2}$ levels (microaerophilic), and under psychrophilic conditions ${ }^{[30]}$, and considered as an ideal choice for various commercial exploitation in the industrial biotechnology sector.

The pure fungal isolate has appeared as the velvety and sulcate appearance of colonies with green color on PDA plates. The reverse side of the colonies was yellow. Based on the previously mentioned macroscopic and microscopic morphologies of the fungal isolate identified as Penicillium roqueforti by the aid of the universal manuals ${ }^{[31,32]}$.

Generally, few reports have been made on the synthesis of metal nanoparticles using Penicillium species. Taha et al. [33] reported that the synthesis of silver nanoparticles was carried out by Penicillium italicum. Also, Ghomi et al. ${ }^{[34]}$ studied the biosynthesis of zirconium nanoparticles using different Penicillium species. Farah et al. ${ }^{[35]}$ demonstrated the biosynthesis of different metallic nanoparticles, such as silver, copper, and aluminum, with a small average size and high monodispersity through reduction of toxic metal salts using the following fungal isolates: Alternaria alternata, Penicillium duclauxii, and Aspergillus niger respectively. The appearance of brown color was confirmed following the 
study by Gottimukkala et al. ${ }^{[36]}$, who suggested that brown color formation, resulted from synthesized iron nanoparticles when they used the green tea extract. This color change was due to surface plasmon resonance ${ }^{[37]}$. The fine brick-red precipitate indicated the rapid formation of iron oxide $\left(\mathrm{Fe}_{3} \mathrm{O}_{4}\right)$ nanoparticles [38].

The UV-Vis absorbance value of IONPs was observed in the region of 204-266 nm, which indicated the formation of IONPs. The IONPs band recorded by Basavegowda et al. ${ }^{[39]}$ showed a peak at $250 \mathrm{~nm}$.

The obtained EDX spectrum of the synthesized iron nanoparticles was similar to the results recorded by Subhashini et al. ${ }^{[38]}$. The additional peaks for oxygen and carbon were observed due to the adsorbed oxygen and the percentage of biomass during biosynthesis. The analysis results of IONPs using TEM exhibited a large aggregation, which is due to the magnetostatic reaction and surface tension between the magnetic nanoparticles ${ }^{[40]}$. The aggregated 10 nanoparticles were about 5-16 $\mathrm{nm}$. Some researchers even argue that small size may provide some advantages, such as improved in vivo compatibility ${ }^{[41]}$. Regarding the XRD pattern of biosynthesized IONPS was characterized by basic reflection appearing at a $2 \varnothing$ value of $44.60^{\circ}$ and additional peaks at $11.82^{\circ}, 30.00^{\circ}$, $35.24^{\circ}, 57^{\circ}$, and $62.8^{\circ}$, which are similar to that reported by Yuan et al. ${ }^{[40]}$. The wide peaks are related to the small size of particles. The $\mathrm{Fe}_{3} \mathrm{O}_{4}$ coated with silica was a slight increase in the region $20^{\circ}<2 \theta<30^{\circ}$. This is because amorphous silica has a halo in that region (maximum at $2 \theta \sim 26^{\circ}$ ), which can cause peak broadening, consequently lowering its intensity.

The evaluation of the IONPs as an antibacterial agent is relatively new. In the current study, the obtained results are correlated with those obtained by other researchers [42], who reported that iron oxide nanoparticles showed good antibacterial activity on $E$. coli and $P$. vulgaris than the $S$. aureus bacterial strains. Moreover, the inhibition zone diameter was different for the different bacterial types ${ }^{[43]}$. The primary mechanism by which the nanoparticles of iron oxide affected the tested organisms might be through oxidative stress caused by redox oxidative stress, including radicals, such as superoxide radicals $\left(\mathrm{O}^{-2}\right)$, hydroxyl radicals $(-\mathrm{OH})$, and hydrogen peroxide $\left(\mathrm{H}_{2} \mathrm{O}_{2}\right)$ as well as singlet oxygen $\left(\mathrm{O}_{2}\right)$, which cause the damage of the proteins and DNA in the bacterial cell, leading to the inhibition of most pathogenic bacteria, such as $S$. aureus and $E$. coli ${ }^{[4]]}$. Also, the obtained antifungal results have confirmed the study by Parveen et al. ${ }^{[45]}$, who detected significant antifungal activities of iron oxide nanoparticles toward Aspergillus niger and Mucor piriformis. While Devi et al. ${ }^{[46]}$ tested biosynthesized iron oxide nanoparticles using Platanus orientalis against $A$. niger and $M$. piriformis. Their results showed significant antifungal activities against $M$. piriformis in comparison with $A$. niger. The inhibitory effect of IONPs on mycelial growth of the fungus was explained by Devi et al. ${ }^{[46]}$, who stated that the possibilities of membrane damage caused by direct or electrostatic interaction between iron oxide nanoparticles and cell surfaces, cellular internalization of nanoparticles, and the production of active oxygen species such as $\mathrm{H}_{2} \mathrm{O}_{2}$, in cells due to metal oxides. Alternatively, Seddighi et al. ${ }^{[47]}$ tested the IONPs at $125 \mu \mathrm{g} / \mathrm{ml}$, and they observed that IONPs were less able to inhibit $C$. tropicalis, $C$. albicans, and $C$. glabrata spp. Similar to their findings, it was noted that the antifungal activity of the IONPs and SiIONPs was improved as the concentrations of the IONPS increased.

\section{Conclusion}

This study concerned with biosynthesizing iron oxide nanoparticles (IONPs) from Penicillium roqueforti. The stability and safety of IONPs can be increased by modifying their surface with silica. Biosynthesized iron oxide nanoparticles and their modified form showed enhanced antimicrobial effects against the tested bacterial and fungal pathogens. Furthermore, the results revealed that the modified iron oxide nanoparticles had an antimicrobial impact greater than iron oxide nanoparticles. Therefore, the iron oxide nanoparticles and silica-modified iron oxide nanoparticles could be used as antimicrobial agents against some foodborne pathogens.

\section{Abbreviations}

EDX: Energy dispersive X-ray; PDA: Potato dextrose agar; TEM: Transmission electron microscopy; TEOS: Tetraethyl-orthosilicate; XRD: X-ray diffraction.

\section{ACKNOWLEDGEMENTS}

The authors are grateful to staff members of Food Technology Research Centre, Agriculture Research Centre and staff members of Microbiology Department, Faculty of Science, Ain- Shams University for their kind help and encouragement to accomplish this study. 


\section{Reference}

1. Rawat, S. (2015). Food spoilage: Microorganisms and their prevention. Asian J. Plant Sci., 5(4): 47- 56.

2. Hneini, F. and Nawas, T. (2019). Sporeformers: major contaminants of cheese manakish. Int. J. Dev. Res., 9 (11): 31387 31390.

3. Kim, S. W., Kim, K. S., Lamsal, K., Kim, Y. J., Kim, S. B., Jung, M. Y. and Lee, Y. S. (2009). An in vitro study of the antifungal effect of silver nanoparticles on oak wilt pathogen Raffaelea sp. J. Microbiol Biotechnol., 19(8): 760 - 764.

4. Raghunath, A. and Perumal, E. (2017). Metal oxide nanoparticles as antimicrobial agents: $\mathrm{A}$ promise for the future. Int. J. Antimicrob. Agents, 49 (2): 137- 152.

5. Sayes, C. M., Gobin, A. M., Ausman, K. D., Mendez, J., West, J. L. and Colvin, V.L. (2005). Nano-C60 cytotoxicity is due to lipid peroxidation. Biomaterials, 26(36): 7587 7595.

6. Guo, J., Padilla, R. J., Ambrose, W., De Kok, I. J. and Cooper, L. F. (2007). The effect of hydrofluoric acid treatment of $\mathrm{TiO} 2$ grit blasted titanium implants on adherent osteoblast gene expression in vitro and in vivo. Biomaterials, 28(36): $5418-5425$.

7. Ueng, T. H., Kang, J. J., Wang, H. W., Cheng, Y. W., and Chiang, L. Y. (1997). Suppression of microsomal cytochrome P450-dependent monooxygenases and mitochondrial oxidative phosphorylation by fullerenol, a polyhydroxylated fullerene C60. Toxicology Letters, 93(1): 29-37.

8. Saleh, N. B., Chambers, B., Aich, N., Plazas-Tuttle, J., Phung-Ngoc, H. N. and Kirisits, M. J. (2015). Mechanistic lessons learned from studies of planktonic bacteria with metallic nanomaterials: Implications for interactions between nanomaterials and biofilm bacteria. Front Microbiol., 6: 677.

9. Mastuli, M. S., Roshidah, R., Mahat, A. M., Saat, N. and Kamarulzaman, N. (2012). Sol-gel synthesis of highly stable nano sized $\mathrm{Mg} \mathrm{O}$ from magnesium oxalate dihydrate. J. Adv. Mater. Res., 545: 137- 142.
10. Das, R. K., Pachapur, V. L., Lonappan, L., Naghdi, M., Pulicharla, R., Maiti, S., Cledon, M., Dalila, L. M. A., Sarma, S. J. and Brar, S. K. (2017). Biological synthesis of metallic nanoparticles: plants, animals and microbial aspects. Nanotechnol. Environ. Eng., 2(1): 1 - 21.

11. Al-Shmgani, H. S., Mohammed, W. H., Sulaiman, G. M. and Saadoon, A. H. (2017). Biosynthesis of silver nanoparticles from Catharanthus roseus leaf extract and assessing their antioxidant, antimicrobial, and wound-healing activities. Artif. Cells Nanomed. and Biotechnol., 45(6): 1234 1240.

12. Luo, K., Jung, S., Park, K. H. and Kim,Y. R. (2018). Microbial biosynthesis of silver nanoparticles in different culture media. J. Agric. Food Chem., 66(4): 957-962.

13. Rao, A., Bankar, A., Kumar, A. R., Gosavi, S. and Zinjarde, S. (2013). Removal of hexavalent chromium ions by Yarrowia lipolytica cells modified with phyto-inspired $\mathrm{Fe}^{0} / \mathrm{Fe}_{3} \mathrm{O}_{4}$ nanoparticles. J. Contam. Hydrol., 146: 63- 73.

14. Mohamed, Y. M., Azzam, A. M., Amin, B. H. and Safwat, N. A. (2015). Mycosynthesis of iron nanoparticles by Alternaria alternata and its antibacterial activity. Afr. J. Biotechnol., 14(14): $1234-1241$.

15. Subramaniyam, V., Subashchandrabose, S. R., Thavamani, P., Megharaj, M., Chen, Z. and Naidu, R. (2015). Chlorococcum sp.MM11- a novel phyco-nanofactory for the synthesis of iron nanoparticles. J. Appl. Phycol., 27(5): 1861- 1869.

16. Bharde, A., Wani, A., Shouche, Y., Joy, P. A., Prasad, B. L. and Sastry, M. (2005). Bacterial aerobic synthesis of nanocrystalline magnetite. J. Am. Chem. Soc., 127(26): 9326 - 9337.

17. Singh, P., Kim, Y. J., Zhang, D. and Yang, D.C. (2016). Biological synthesis of nanoparticles from plants and microorganisms. Trends Biotechnol., 34(7): 588 - 599.

18. El-Baz, A. F., El-Batal, A. I., Abomosalam, F. M., Tayel, A. A., Shetaia, Y. M. and Yang, S. T. (2016). Extracellular biosynthesis of antiCandida silver nanoparticles using Monascus purpureus. J. basic Microbiol., 56 (5): 531- 540. 
19. Toghueo, R. M. K. and Boyom, F. F. (2020). Endophytic Penicillium species and their agricultural, biotechnological, and pharmaceutical applications. Biotech., 10(3): 1- 35.

20. Behera, S. S., Patra, J. K., Pramanik, K., Panda, N. and Thatoi, H. (2012). Characterization and evaluation of antibacterial activities of chemically synthesized iron oxide nanoparticles. W J N S E, 2(04): 196 - 200.

21. Kandpal, N. D., Sah, N., Loshali, R., Joshi, R. and Prasad, J. (2014). Coprecipitation method of synthesis and characterization of iron oxide nanoparticles. J. Sci. Ind. Res. India, 73(2): 87 90.

22. Kandibanda, S. R., Gundeboina, N., Das, S. and Sunkara, V. M. (2018). Synthesis, characterisation, cellular uptake and cytotoxicity of functionalised magnetic ruthenium (II) polypyridine complex core-shell nanocomposite. J. Photochem. Photobiol. Biol., 178: 270 - 227.

23. White, T. J., Bruns, T., Lee, S. J. W. T. and Taylor, J. (1990). Amplification and direct sequencing of fungal ribosomal RNA genes for phylogenetics. PCR protocols: a guide to methods and applications, 18(1): 315 - 322.

24. Mazumdar, H. and Haloi, N. (2011). A study on biosynthesis of iron nanoparticles by Pleurotus sp.. J. Microbiol. Biotechnol. Res., 1(3):39 - 49.

25. Khosroshahi, M. E. and Ghazanfari, L. (2010). Preparation and characterization of silica-coated iron-oxide bio-nanoparticles under N2 gas. Physica. E, 42(1): $1824-1829$.

26. Azam, A., Ahmed, A. S, Oves, M., Khan, M. S., Habib, S. S. and Memic, A. (2012). Antimicrobial activity of metal oxide nanoparticles against Gram-positive and Gram-negative bacteria: a comparative study. Int. J. Nanomedicine, 7: 6003.

27. Margabandhu, M., Sendhilnathan, S., Maragathavalli, S., Karthikeyan, V. and Annadurai, B. (2015). Synthesis characterization and antibacterial activity of iron oxide nanoparticles. Glob. J. Bio Sci. Biotechnol., 4(4): 335 - 341.
28. Madhyastha, M. S. and Bhat, R.V. (1984). Aspergillus parasiticus growth and aflatoxin production on black and white pepper and the inhibitory action of their chemical constituents. Appl. Environ. Microbiol., 482: 376-379.

29. Duncan, D. B. (1955). Multiple range and multiple F tests. Biometrics, 11(1): 1- 42.

30. Hymery, N., Puel, O., Tadrist, S., Canlet, C., Le Scouarnec, H., Coton, E. and Coton, M. (2017). Effect of PR toxin on THP1 and Caco-2 cells: an in vitro study. World Mycotoxin J., 10(4): $375-386$.

31. Pitt, J. I. (1979). The genus Penicillium and its teleomorphic states eupenicillium and talaromyces. Commonwealth scientific and industrial research organization. Academic Press Inc. Ltd. London UK.p. 634.

32. De Hoog, G. S., Guarro, J., Gené, J. and Figueras, M. J. (2000). Atlas of clinical fungi (Ed.2). Centraalbureau voor Schimmelcultures (CBS). Utrecht, The Netherlands.

33. Taha, Z.K.., Hawar, S.N. and Sulaiman, G.M. (2019). Extracellular biosynthesis of silver nanoparticles from Penicillium italicum and its antioxidant, antimicrobial and cytotoxicity activities. Biotechnol. Lett., 41(8): 899 - 914.

34. Ghomi, A. R. G., Mohammadi-Khanaposhti, M., Vahidi, H., Kobarfard, F., Reza, M. A. S. and Barabadi, H. (2019). Fungus-mediated Extracellular Biosynthesis and Characterization of Zirconium Nanoparticles Using Standard Penicillium Species and Their Preliminary Bactericidal Potential: A Novel Biological Approach to Nanoparticle Synthesis. Iran J. Pharm. Res., 18(4): 2101.

35. Farah, S. S., El-Taher, E.M., Shetaia, Y. M., ElAdly, R. A. and El-Desouki, D. S. (2020). Biosynthesis of metallic nanoparticles using fungi and their applications. J. Biotechnol., 8(1): 8- 20.

36. Gottimukkala, K. S. V., Harika, R. P. and Zamare, D. (2017). Green synthesis of iron nanoparticles using green tea leaves extract. J. Nanomed. Biother. Discovery, 7(151.10): 4172. 
37. Torabian, P., Ghandehari, F. and Fatemi, M. (2018). Biosynthesis of iron oxide nanoparticles by cytoplasmic extracts of bacteria lactobacillus casei. Asian J. Green Chem., 2 (3): 181 - 188.

38. Subhashini, G., Ruban, P. and Daniel, T. (2018). Biosynthesis and characterization of magnetic $\left(\mathrm{Fe}_{3} \mathrm{O}_{4}\right)$ iron oxide nanoparticles from a red seaweed gracilaria edulis and its antimicrobial activity. Int. J. adv., 3(10): 184 - 189.

39. Basavegowda, N., Magar, K. B. S., Mishra, K. and Lee, Y. R. (2014). Green fabrication of ferromagnetic $\mathrm{Fe}_{3} \mathrm{O}_{4}$ nanoparticles and their novel catalytic applications for the synthesis of biologically interesting benzoxazinone and benzthioxazinone derivatives. New J. Chem., 38(11): $5415-5420$

40. Yuan, M. L., Tao, J. H., Yan, G. J., Tan, M.Y. and Qiu, G. Z. (2010). Preparation and characterization of $\mathrm{Fe} / \mathrm{SiO}_{2}$ core/shell nanocomposites. T Nonferr. Metal Soc., 20(4): $632-636$.

41. Sharafi, Z., Bakhshi, B., Javidi, J. and Adrangi, S. (2018). Synthesis of Silica-coated Iron Oxide Nanoparticles: Preventing Aggregation without Using Additives or Seed Pretreatment. Iran J. Pharm. Res., 17(1): 386 - 395.

42. Prabhu, Y. T., Rao, K. V., Kumari, B. S., Kumar, V. S. S. and Pavani, T. (2015). Synthesis of $\mathrm{Fe}_{3} \mathrm{O}_{4}$ nanoparticles and its antibacterial application. Int. Nano Lett., 5(2): 85-92.
43. Asab, G., Zereffa, E. A. and Abdo Seghne, T. (2020). Synthesis of silica-coated Fe3O4 nanoparticles by microemulsion method: characterization and evaluation of antimicrobial activity. Int. J. Biomater, Article ID 4783612. https://doi.org/10.1155/2020/4783612.

44. Ibrahim, H. M. (2015). Green synthesis and characterization of silver nanoparticles using banana peel extract and their antimicrobial activity against representative microorganisms. J Radiat Res Appl Sc, 8(3): 265 - 275.

45. Parveen, S., Wani, A. H., Shah, M. A., Devi, H. S., Bhat, M. Y. and Koka, J. A. (2018). Preparation, characterization and antifungal activity of iron oxide nanoparticles. Microb. Pathog., 115: 287 292.

46. Devi, H. S., Boda, M. A., Shah, M. A., Parveen, S. and Wani, A. H. (2019). Green synthesis of iron oxide nanoparticles using Platanus orientalis leaf extract for antifungal activity. Green Process Synth., 8(1): 38 - 45.

47. Seddighi, N. S., Salari, S. and Lzadi, A. R. (2017). Evaluation of antifungal effect of iron-oxide nanoparticles against different Candida species. let. Nanobiotechnol., 11(7): 883-888. 